\title{
Performance measures of game activity and team effectiveness in competitive youth soccer
}

\author{
ALLEN J. SCHUH \\ California State University, Hayward, California
}

\begin{abstract}
Analysis of performance measures over 49 important games for a youth soccer team (males under 12 years of age) indicated significant reliability for win-loss record, goals scored, goal kicks, direct free kicks, and offsides calls. One performance measure had no reliability: indirect free kicks other than for offsides. Throw-ins became less reliable over the season. Corner kicks, goalkeeper touches of the ball, and goalkeeper saves increased in reliability over the season. Effectiveness measures for the attacking players were relatively stable within the team for scoring the first and/or deciding goal in a match. Over the season, it became more difficult for both teams to score goals. The effectiveness measure for the defensive unit (number of scoreless halves for both teams) was stable. The multiple regression equation $(R=.79)$ developed on the first $25 \mathrm{im}$ portant games accurately predicted 21 of 24 game results $(p<.001)$ during the last half of the season.
\end{abstract}

Soccer is the most popular athletic sport in the world (Chyzowych, 1978; International Football Association Board, 1984). Probably what makes the game so popular is that it is about the simplest team game played by members of the species (L. Harris, 1978; Sellin, 1977). In some American communities, children start playing recreationally before 6 years of age, an early age considering most of these children have neither the sensory motor capacity nor mental development to write their own names (Liebert, Poulos, \& Strauss, 1974; Munn, 1974).

Measures of effectiveness can be dynamic (Anastasi, 1976; Cronbach, 1984; Guion, 1965; McCormick \& Tiffin, 1974; Nunnally, 1970; L. Siegel \& Lane, 1982), especially with youthful players who are still growing in height, weight, mental capacity, and personal character (Ambron \& Brodzinsky, 1979; Liebert et al., 1974; Munn, 1974; Nash, 1978; Ripple, Biehler, \& Jaquish, 1982; Vander Zanden, 1981).

Researchers might be interested in how the reliability of the most frequently used performance measures changes during the game and over the season, and whether such measures relate to team success. As in other sports, there are decisions to be made (Carter \& Machol, 1978; Cook, 1977; D'Esopo \& Lefkowitz, 1977; Goode, 1976; Lindsey, 1977; Machol, Ladany, \& Morrison, 1976; Marshall, 1974; Mitchell \& Michel, 1977; Pollard, Benjamin, \& Reep, 1977; Price \& Rao, 1977). If a team is doing well, the coach is more likely to commit it to expensive tournament play outside of the geographical area. But the measures of game activity and effectiveness must be reliable. The coach does not want the players to travel far and then to be beaten.

The author's mailing address is: Department of Management Sciences, School of Business and Economics, California State University, Hayward, CA 94542.
There are also decisions to be made about the withinteam structure (Dalton, Todor, Spendolini, Fielding, \& Porter, 1980; Dyer, Miller, \& Morse, 1978; Gagne, 1962; Huber, Ullman, \& Leifer, 1974; Mitchell \& Michel, 1977; Price \& Rao, 1977). If a player of the offensive unit has many shots on the goal and a high scoring efficiency, the coach will want to give that player more playing time.

The classification of tasks is often based on whether the job is independent of the effort of others, dependent upon one other person, or dependent upon the cooperative efforts of three or more persons (Bass \& Vaughan, 1966; Campbell, 1971; Dyer et al., 1978; Gagne, 1962; Guion, 1965; Machol et al., 1976; McCormick \& Tiffin, 1974; L. Siegel \& Lane, 1982). In contrast to the attacking players, who can score a goal based on individual effort, the defensive unit, consisting of the goalkeeper, fullbacks, and defensive midfielders, must work truly as a team to prevent the opponent from scoring (Chyzowych, 1978; Hughes, 1973; Jones \& Welton, 1979; I. R. Schmid, McKeon, \& M. R. Schmid, 1968; Sellin, 1976, 1977; Vogelsinger, 1982). The usual arrangement in soccer is to have the fullbacks contain the attackers and stay goal-side of the ball, while the midfielders try to collect the ball from the attacker. The goalkeeper protects the goal in case the attacker gets past the other defenders. Thus, it is difficult to evaluate individual defensive players because of their team interactions. Defensive unit effectiveness might be judged by the number of shutout games or number of low scoring games. Attackers can be evaluated based on traditional individual measures of goals and assists, the timing of a goal, and the goal's effect on the outcome of the game (Chyzowych, 1978; Jones \& Welton, 1979; I. R. Schmid et al., 1968; Sellin, 1976, 1977; Vogelsinger, 1982).

Information on the reliability of performance measures and their raw score weight in multiple regression against 
the win-loss criterion would give the active coach more information on what to focus on in practice (Goode, 1976; Marshall, 1974). Whatever is highly reliable and correlates highly with win-loss should be practiced more. Time is scarce for drill on skills, tactics, and strategy of play.

The purpose of this report is to describe a complete analysis of one year's worth of game experience for a youth soccer team. The team, Ballistic United of Pleasanton, California, had a successful season and won the Northern California State Title. During the 84-game playing year described in this paper, the competition consisted of league and state title games against other competitive teams from within California, and tournament and practice against teams from California and surrounding states and from Alberta and British Columbia, Canada.

\section{METHOD}

\section{Participants}

Participants were 16 males born in 1973 or 1974 who were residents of Pleasanton, California (population 40,000) selected during league tryouts from a pool of about 350 enrolled male soccer players who had at least 1 year of previous experience. The team (Ballistic United Soccer Club or BUSC) practiced about $4 \mathrm{~h}$ a week and played their games on the weekends between July 1984 and May 1985.

\section{The Coach}

The team's volunteer coach had 17 years of experience. He continued coaching after his own children were grown. He had won three previous state titles.

\section{Data Recorder}

The recorder of the data was the author, who had been a university professor for 16 years and had been a soccer fan since his college experience. He held the " $D$ " state soccer coaching license. He was also a registered United States Soccer Federation Referee.

\section{Data Recorded}

Records were kept for each half of all games for which goals were set up with nets, the fields marked, and a referee assigned to the game. Games lasted $60 \mathrm{~min}$. Descriptors for each game were: game number, opponent's name, field where the game was played, date, time of day, conditions of weather and playing field, game purpose (practice, league, tournament, or state title competition), age group of opponent, referee system, size of field, color of jerseys, and the goalkeeper's shirt color.

A $6 \times 15$ hexagonal grid overlaid the penalty area, which allowed a record of shots on the goal by grid marker. A record was made of who took the shot, time if a goal, and who assisted. Records were also kept of number of goals scored, game outcome (won-lost-tied), number of times the goalkeeper played the ball, number of saves by the goalkeeper, number of goal kicks by each team, number of corner kicks, number of direct free kicks awarded because of fouls, number of indirect free kicks awarded for minor infractions, number of times the team was awarded ball possession because the other team was offsides, and number of throw-ins. A full description of these measures is provided by several authors (Chyzowych, 1978; L. Harris, 1978; P. E. Harris \& L. R. Harris, 1983; Hughes, 1973; International Football Association Board, 1984; Jones \& Welton, 1979, Lover, 1975, 1978, 1980; I. R. Schmid et al., 1968).

\section{Analysis Procedures}

The season of 84 games began in July 1984 with the first practice game against a group of older females and ended with winning the state title in May 1985. The season was split into halves. During the first 41 games, there were 25 important games against males of the same age group. The 16 games excluded from consideration were against males or females of older age groups or were against males of the same age group but the game's purpose was practice. Similar rationale was used for the next $\mathbf{4 3}$ games, which contained 24 against males of the same age group where the game was important. Important games were league games, state title games, and tournament games.

The data for each game were kept separate for first and second halves, which allowed a reliability comparison (Anastasi, 1976; Cronbach, 1984; Guilford, 1954; Guion, 1965; McNemar, 1969; Nunnally, 1970; L. Siegel \& Lane, 1982; S. Siegel, 1956). The data for the two halves were correlated and tested for significance. The significant correlations were then combined to form the whole game reliability estimate by the Spearman-Brown procedure (Guilford, 1954; Nunnally, 1970).

The reliable whole game totals were put into a multiple regression equation with the game result (win-loss) as criterion for the first 25 important games and were cross-validated (Anastasi, 1976; Cronbach, 1984; Guilford, 1954; Guion, 1965; McNemar, 1969; L. Siegel \& Lane, 1982) for the last 24 important games.

\section{RESULTS}

The team's mission effectiveness was reflected in the win-loss record. All chi-square (Hays, 1973; S. Siegel, 1956) comparisons were not significant: for practice versus important games, and for both halves of the season. BUSC won all league and state title games, most games in tournaments, and most practice games. The record for important games was 22-0-3 and 21-1-2. Overall, the record was 33-2-6 and 30-5-8.

For the first half of the season, BUSC scored 3 goals more frequently than any other number, and the median was 4 . For opponents, the mode and median were 1 . For the second half of the season, the mode and median were 2 for BUSC and 0 for opponents. Chi-square tests showed all comparisons to be significantly different beyond the .05 level.

An analysis was made of the time remaining in the half before the first goal. The median time was $15 \mathrm{~min}$, and there was no significant difference between halves of the game or halves of the season.

An analysis was made of where the goals came from. During both halves of the season, the probability of a goal's coming from left, center, or right of the goal was equal for BUSC and opponents. Starting with Row 1 on the goal line and working into the midfield, shots further out (Rows 3 to 6) were more effective than either further in or further out for BUSC both halves of the season and for opponents in the last half of the season $(p<.05)$.

An analysis was made of the effectiveness of the first and deciding goals, penalty kick efficiency, and goalsto-shots ratio for BUSC attacking players. The correlation of who contributed to the first goal between both halves of the season was $r=.915, p<.05$ (Sockloff \& Edney, 1972). First goal correlated with deciding goal $(r=.94, p<.05)$ the last half of the season. One player led for assists for both halves of the season. Another player who was the poorest for penalty kick efficiency was the most efficient on goals-to-shots ratio. A third player took the most shots and led on goals and assists for first goals and deciding goals, but had the second worst goals-to-shots ratio.

An analysis was made of the goal efficiency for BUSC and opponents. The number of goals during the first 25 
Table 1

Measures of Effectiveness by Game Activity

\begin{tabular}{|c|c|c|c|c|c|c|c|}
\hline & \multicolumn{4}{|c|}{ Reliability } & \multicolumn{2}{|c|}{ Means } & \multirow{2}{*}{$\begin{array}{l}\text { Regression } \\
\text { Weights for } \\
\text { Raw Scores }\end{array}$} \\
\hline & $\begin{array}{c}\text { First } \\
\text { Half Season* }\end{array}$ & SB† & $\begin{array}{c}\text { Second } \\
\text { Half Season* }\end{array}$ & $\mathrm{SB} \dagger$ & $\begin{array}{c}\text { First } \\
\text { Half Season } \\
\end{array}$ & $\begin{array}{c}\text { Second } \\
\text { Half Season } \\
\end{array}$ & \\
\hline Shots & .611 & .759 & .633 & .775 & 12.80 & 10.79 & .0261 \\
\hline Goals & .668 & .901 & .526 & .689 & 2.84 & 1.59 & .1302 \\
\hline Win-Loss & .419 & .590 & .775 & .873 & 1.00 & 1.00 & Criterion \\
\hline Goalkeeper Touches & $(.147)$ & & .282 & .439 & 11.42 & 11.40 & \\
\hline Goalkeeper Saves & $(.042)$ & & .275 & .431 & 3.90 & 4.47 & \\
\hline Goal Kicks & .257 & .408 & .507 & .672 & 6.68 & 5.81 & -.0339 \\
\hline Corner Kicks & $(.198)$ & & .292 & .452 & 2.60 & 2.40 & \\
\hline Direct Free Kicks & .337 & .504 & .347 & .515 & 5.18 & 4.50 & .0558 \\
\hline Indirect Free Kicks & $(.137)$ & & $(.022)$ & & .42 & .65 & \\
\hline Offsides & .611 & .759 & .603 & .752 & 1.72 & 1.06 & -.0641 \\
\hline Throw-ins & .379 & .549 & $(.227)$ & & 19.16 & 22.43 & .0215 \\
\hline Constant & & & & & & & -.0691 \\
\hline
\end{tabular}

*A correlation of .235 was required for statistical significance at the .05 level with a one-tailed $t$ test for the first 25 games (first half season), and a correlation of .24 was required for the next 24 games (second half season). The correlations in parentheses were not significant. $†$ Spearman-Brown formula reliability estimates were calculated only if the first- and secondhalf intercorrelations were significant.'

important games was 121 for BUSC and 21 for opponents. For the next 24 important games, BUSC scored 62 goals and opponents scored 10 . All comparison differences were significantly different beyond the .05 level. Later in the season, it was much harder to get a goal. The goal-toshot ratio dropped accordingly.

An analysis was made of the measure of effectiveness for the defensive units: the number of scoreless game halves to which the other team had been held. The only significant difference was that BUSC had been held scoreless 12 times in the second halves of games during the first half of the season but only 4 times in the second halves of games during the second half of the season $(p<.05)$.

Table 1 shows the measures of effectiveness by game activity. The multiple regression $(R=.79)$ was for the performance measures of game activity with the win-loss criterion for the first half of the season. The weights were applied to the hold out second half of season data and accurately predicted the outcomes of all 21 games $(p<.001)$ that resulted in a win-loss. The formula did not predict the 3 ties.

\section{DISCUSSION}

A relatively straightforward validity study, such as this one, can be useful to the practicing coach. The analysis showed what most observers of the sport had probably assumed, that goals came most frequently from shots taken from within the penalty area. The refinement that this research showed was where exactly those goals came from: the intermediate distance between the goal area line and the penalty area line in a path as wide as the goal area. Practices should focus on delivering the ball to this location and then shooting the ball from this area, and on defending against those shots.

The varying levels of effectiveness of the attacking players suggest that these data should not be aggregated, as is frequently done in reports of game activity. The ratio of shots to goals depends on who is doing the shooting and whether it is from the field or penalty kick mark.

The analysis showed the impact of the long season on team effectiveness. It became much harder for both teams to score goals later in the season. Perhaps because defense is truly a team effort, many games with constant repetition are required for the defense to learn the team skills necessary to shut down offensive maneuver. Advice to a coach would be to work on defense at the beginning of the season to bring the team faster to midseason strength.

It is noteworthy that the attacking players had almost the same number of shots on the goal during both halves of the season, but the shots were less likely to be goals during the last half of the season. Perhaps attacking players look better than they deserve in recreational settings where seasons may only be 12 to 15 games. In such a short season, the defense may never learn to function well together.

Table 1 indicates several points of interest which revolve around the reliability changes over the season. Special note should be made of the increased reliability of the criterion for the second half of the season. The reliability of the criterion is probably a result of the large number of games played by the team. The constant repetition of drills pays off in skill acquisition and, therefore, consistency of the performance by these youthful players. It is likely that the content of the drills transfers to game-related activities.

Similar rationale might be offered for the change in reliability of the performance measures that become more reliable. Table 1 shows that goalkeeper touches, goalkeeper saves, and corner kicks move from random to systematic variance. Further research is needed on the reason for the performance measure changes. All three performance measures reflect actions by the defensive unit, which we know develops skill as the season continues.

Why the throw-ins should decrease in reliability over the season is not known. The author speculates about the reason for the throw-in changes: early in the season, the throw-in may have been awarded to the one team because a player of the other team has kicked the ball out of bounds when he did not know what else to do with it, whereas later in the season, when the defense has gained more confidence, perhaps the player tried to keep the ball inbounds and tried to make a pass down the touch line. Future research should look at what caused the throwin: accidental or deliberate sending of the ball into touch.

When the author examined the details of the multiple regression formula, he was surprised to see the relative contribution of the variables. Goal kicks and offsides have negative weights, which means that when the team was awarded possession of the ball for either of these reasons, the other team had been attacking. The important issue here is that the other team was attacking. If one examines the ratio of the regression weights and means, it is seen that being called for offsides is almost as important to the attacking team as if they had successfully scored a goal. There are coaches who tell their attacking players not to worry about offsides calls. These results would suggest that those coaches are 
correct in their advice to their players, perhaps with the added instruction that the players not be obvious, but a half step on a defender can make a difference.

The results reported here are for youthful players still a long way from maturity. Whether the findings generally, and specifically with regard to the prediction formula, would hold for older players remains to be investigated.

Further investigation should go beyond the standard measures of game performance reported here. These measures were simple and straightforward: If the ball went into touch and the referee awarded possession to the other team, the data recorder simply wrote down this objective measure. The effect of accumulating these miasures and correlating them with performance effectiveness resulted in a highly significant prediction equation for game result which held up under cross validation to the second half of the season.

The next step in research should be to derive other indexes of game activity for the midfielders and defenders that do not come from the traditional score card. The importance of the defensive unit was shown, yet there are no well-recognized measures of individual midfielder or defensive player activity similar to that for the attacking players. If we had such measures, we might explain game activity better for the benefit of players, their coaches, and the spectators.

\section{REFERENCES}

AMBron, S. R., \& Brodzinsky, D. (1979). Lifespan human development. New York: Holt, Rinehart \& Winston.

Anastasi, A. (1976). Psychological testing. New York: Macmillan.

Bass, B. M., \& Vaughan, J. A. (1966). Training in industry: The psychology of learning. Belmont, CA: Wadsworth.

Campbell, J. P. (1971). Personnel training and development. Annual Review of Psychology, 22, 565-602.

CARTER, V., \& MACHOL, R. E. (1978). Optimal strategies on fourth down. Management Science, 24, 1758-1762.

CHYzowych, W. (1978). The official soccer book of the United States Soccer Federation. New York: Rand McNally.

Cook, E. (1977). An analysis of baseball as a game of chance by the Monte Carlo method. In S. P. Ladany \& R. E. Machol (Eds.), Optimal strategies in sports (pp. 50-54). Amsterdam: North-Holland.

CRONBACH, L. J. (1984). Essentials of psychological testing. New York: Harper \& Row.

Dalton, D. R., Todor, W. D., Spendolini, M. J., Fielding, G. J., \& PORTER, L. W. (1980). Organizational structure and performance: A critical review. Academy of Management Review, 5, 49-64.

D'EsoPo, D. A., \& LEFKOWITZ, B. (1977). The distribution of runs in the game of baseball. In S. P. Ladany \& R. E. Machol (Eds.), Optimal strategies in sports (pp. 55-62). Amsterdam: North-Holland.

DYer, J. S., Miller, R. A., \& MORSE, J. J. (1978). A framework for the study of work settings. Management Science, 24, 1393-1403.

GAGNE, R. M. (ED.). (1962). Psychological principles in system development. New York: Holt, Rinehart \& Winston.

GoodE, M. (1976, August). Teaching statistical concepts with sports. Paper presented to the American Statistical Association, Boston, MA.

GuIlford, J. P. (1954). Psychometric methods. New York: McGraw-Hill.

Guion, R. M. (1965). Personnel testing. New York: McGraw-Hill.

HARRIS, L. (1978). Futbol means soccer: Easy steps to understanding the game of soccer. Manhattan Beach, CA: Soccer for Americans.

HARRIS, P. E., JR., \& HARRIS, L. R. (1983). Fair or foul: The complete guide to soccer officiating in America. Manhattan Beach, CA: Soccer for Americans.

Hays, W. L. (1973). Statistics for the social sciences. New York: Holt, Rinehart \& Winston.

Huber, G. P., Ullman, J., \& Leifer, R. (1974). Optimum organization design: An analytic-adoptive approach. Academy of Management Review, 4, 567-578.
Hughes, C. F. C. (1973). Soccer tactics and teamwork. Wakefield, South Yorkshire, England: EP Publishing.

InTERnational Football Association Board. (1984). Laws of the game and universal guide for referees. New York: United States Soccer Federation.

Jones, K., \& Welton, P. (1979). Soccer skills \& tactics. New York: Crown.

Liebert, R. M., Poulos, R. W., \& Strauss, G. D. (1974). Developmental psychology. Englewood Cliffs, NJ: Prentice-Hall.

LiNDSEY, G. R. (1977). A scientific approach to strategy in baseball. In S. P. Ladany \& R. E. Machol (Eds.), Optimal strategies in sports (pp. 1-30). Amsterdam: North-Holland.

Lover, S. F. (1975). Association football laws illustrated. London: Pelham Books.

LOVER, S. F. (1978). Association football match control: An illustrated handbook for the football referee. London: Pelham Books.

LOVER, S. F. (1980). The illustrated soccer quiz book. Chicago: Rand McNally.

Machol, R. E., LadanY, S. P., \& MorRison, D. G. (EDS.). (1976). Management science in sports. Amsterdam: North-Holland.

Marshall, J. (1974, Jan. 14). Doing it by the numbers. Sports Illustrated, 42.

MCCoRMicK, E. J., \& Tiffin, J. (1974). Industrial psychology. Englewood Cliffs, NJ: Prentice-Hall.

McNemar, Q. (1969). Psychological statistics. New York: Wiley.

Mitchell, C. R., \& Michel, A. J. (1977). The valuation of a baseball player. In S. P. Ladany \& R. E. Machol (Eds.), Optimal strategies in sports (pp. 42-45). Amsterdam: North-Holland.

MunN, N. L. (1974). The growth of human behavior. Boston: Houghton Mifflin.

Nash, J. (1978). Developmental psychology. Englewood Cliffs, NJ: Prentice-Hall.

NuNNALLY, J. C., JR. (1970). Introduction to psychological measurement. New York: McGraw-Hill.

Pollard, R., Benjamin, B., \& Reep, C. (1977). Sport and the negative binomial distribution. In S. P. Ladany \& R. E. Machol (Eds.), Optimal strategies in sports (pp. 188-195). Amsterdam: NorthHolland.

Price, B., \& RAO, A. G. (1977). A model for evaluating player performance in professional basketball. In S. P. Ladany \& R. E. Machol (Eds.), Optimal strategies in sports (pp. 116-122). Amsterdam: NorthHolland.

RIPPLE, R. E., BIEHLER, R. F., \& JAQUiSh, G. A. (1982). Human development. Boston: Houghton Mifflin.

Schmid, I. R., McKeon, J. L., \& Schmid, M. R. (1968). Skills and strategies of successful soccer. Englewood Cliffs, NJ: Prentice-Hall.

SELlin, E. (1976). The inner game of soccer. Mountain View, CA: World Publications.

Sellin, E. (1977). Soccer basics. Mountain View, CA: World Publications.

SiegeL, L., \& LANe, I. M. (1982). Personnel and organizational psychology. Homewood, IL: Irwin.

SIEGEL, S. (1956). Nonparametric statistics for the behavioral sciences. New York: McGraw-Hill.

SockLOFF, A. J., \& EDNEY, J. N. (1972). Some extension of Student's $\mathrm{t}$ and Pearson's $\mathrm{r}$ central distributions. Philadelphia, PA: Temple University, Measurement and Research Center.

VANDER ZANDEN, J. W. (1981). Human development. New York: Knopf.

VOGELSINGER, H. (1982). The challenge of soccer: A handbook of skills, techniques, and strategy. La Jolla, CA: Inswinger.

(Manuscript received for publication May 5, 1986.) 